\title{
Comparative study of modeling methods used to simulate initial stresses in prestressed beams towards manual analysis
}

\author{
Mohamad Al-Ilani ${ }^{1}$, Yehya Temsah ${ }^{1}$ \\ ${ }^{1}$ Beirut Arab University, Civil Engineering Department, Beirut, Lebanon
}

\begin{abstract}
Numerical modeling of the prestressing element that generates prestressed effect in beams has always been considered a big challenge. This research compares two methods of modeling; In the first method we used initial stresses predefined stress and in the second method we used the temperature strain. Concrete damage plasticity model (CDP) was used to model the non-linear behavior of concrete material and an elasto-plastic behavior was applied to ordinary and prestressed reinforcement. Truss elements were used to model ordinary and prestressed reinforcement embedded inside the concrete. As a result, Initial Temperature load method showed less error in bottom and top stresses and cambering of beam in comparison with the basic concept method, than predefined method.
\end{abstract}

Keywords: Numerical, Stresses, Camber, Prestressed

\section{INTRODUCTION}

Using prestressed concrete beams is increasing nowadays in residential buildings, commercial, towers and bridges because they are capable of providing high spans with relatively less dimension. Choosing the best method for simulating the pre-compression force in the tendons using finite element models has always been a great challenge. Many researches were conducted to compare between several tendon modeling methods. Kang et al [1] listed 3 modeling techniques to simulate post tensioned beams: tube to tube, multiple spring system and surface to surface contact. They compared these methods with experimental tests and found that using the three methods is acceptable, but the third one is the most reliable. The first two methods gave very accurate results but the computational time is very high in comparison to the surface to surface method.

Kwak et al [2] studies the slip behavior of tendons with concrete surface, where a correlation was done between analytical and experimental studies. It shows the efficient modeling of prestressed concrete beam in ADINA, and very close results have been shown in comparison to experimental results. Analyzing the slip in tendons require nonlinear analysis, where concrete may show nonlinear behavior at anchorage and top face.

Chaudhari,S.V. et al [3] Checked stress strain curves for different mesh size and found that using CDP requires smaller mesh size to get appropriate accuracy.

Using volumetric elements to model prestressed reinforcement requires high computational time, therefore Arab,A., et al [4] compared between two models, one with embedment technique, in which truss elements were used to model prestressed reinforcement and the other is the extrusion technique in which surface to surface method was used. Both techniques were further verified by comparative analysis of the data against the experimental results. In the end of the study they concluded that using the embedded method to simulate prestressed tendons in the concrete beams provides an accurate and numerically efficient alternative in comparison with volumetric method.

Till now very few studies get into prestressing methods of tendons and define the best one to use.

\section{AIM AND SCOPE}

The aim of this research, is to model prestressed concrete beam using the commercial finite element program ABAQUS. Then a parametric study will be performed to investigate the best method to assign prestressed force in the tendons. Final conclusions will be drawn at the end of the research. 


\section{NUMERICAL MODELING}

A $300 \times 600 \mathrm{~mm}$ prestressed concrete beam was modeled with span of five meters, to generate high camber. The element used was C3D8R "An 8-node linear brick". 3 $14 \mathrm{~mm}$ were added as minimum reinforcement at TOP and BOTTOM of the beam, and $4 \varphi 10 \mathrm{~mm}$ as shrinkage reinforcement was used at each side (Figure 1). As for stirrups, $10 \mathrm{~mm}$ bars size were used in this study at two different spacing $(100 \mathrm{~mm}, 200 \mathrm{~mm})$ where the spacing of $100 \mathrm{~mm}$ was used on the first third and the $200 \mathrm{~mm}$ spacing was used in the middle. Ordinary reinforcements and tendons were modeled as rebar elements "Two nodded linear elements". Eight straight tendons of diameter $12.7 \mathrm{~mm}$ were added at $100 \mathrm{~mm}$ height from the bottom face of the beam in order to visualize high top and bottom stresses in addition to high camber.

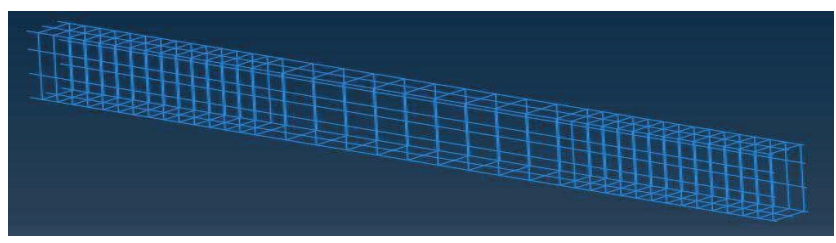

Figure 1.3D view for all ordinary beam reinforcements

The Concrete Damage Plasticity Model was used to define the behavior of concrete. This model was used by many researchers since it works with both static and dynamic load conditions [5-11]. It was derived by Lubliner [12] and developed by Lee and Fenves [13]. It represents the nonlinear behavior of concrete using different input parameters such as: inelastic strain, cracking strain, stiffness degradation and recovery and other parameters. (Figures 4 and 5). As for steel reinforcement and tendons, the plastic behavior was considered in material definition.

Reinforcing steel can be modeled using several methods. For this simulation we considered the elasto-plastic behavior of reinforcing steel, and assumed a perfect bond between concrete and steel. The same process was used for tendons. Own weight was defined as gravitational load for beam.

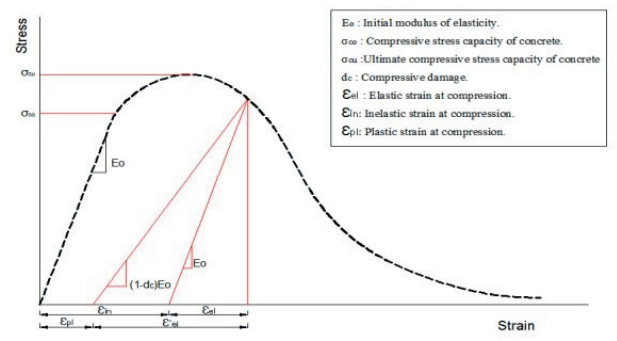

Figure 4. Compressive behaviour of concrete (CDP)

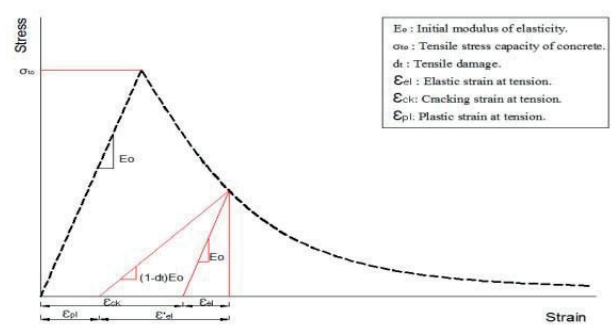

Figure 5. Tensile behaviour of concrete (CDP) 
Two methods were used to define the initial stresses in tendons; Predefined field and initial temperature load. In the predefined stresses, we define the intensity of the stresses from the beginning of the analysis till the end. The second method applied is applying initial temperature load.

Using the initial temperature load method, we defined the magnitude of the temperature which is equivalent to the stresses applied to pre-stressed tendon. In order to apply the prestressing force applied, temperature t (C) can be computed using Eq. 1. Ren et al [14]

$$
C=-\frac{\mathrm{P}}{c \cdot E \cdot A}
$$

$\mathrm{C}$ is the coefficient of linear expansion $\left(1.0 \times 10^{\wedge}-5 \mathrm{MPa} / \mathrm{C}\right) ; \mathrm{P}$ is the force applied after long-term losses in prestressed beam took place. $\mathrm{E}$ is the modulus of elasticity ( $\mathrm{MPa}$ ) and $\mathrm{A}$ is the area in $\mathrm{mm} 2$

\section{Comparison towards manual analysis:}

\subsection{Check for stresses}

Results were compared with manual calculations and are shown in table 1. Stresses were checked using Basic concept method proposed by Nawi [15]. Moreover, Stresses were compared at two locations; top of the concrete beam face and bottom of the concrete beam face under their own dead load.

$$
\mathrm{Fb}=-\frac{P}{A C}+\frac{P_{\theta C}}{l g}-\frac{M C}{l g} \quad \mathrm{Ft}=-\frac{P}{A C}-\frac{P_{\theta C}}{l g}+\frac{M C}{l g}
$$

\begin{tabular}{|c|c|c|c|}
\hline & \multicolumn{3}{|c|}{ STRESSES } \\
\hline & $\begin{array}{c}\text { FEM-initial Temperature } \\
\text { load(MPa) }\end{array}$ & $\begin{array}{c}\text { Manual } \\
\text { Calculation(MPa) }\end{array}$ & \%Error \\
\hline Top Face of the beam & 3.42 & 3.46 & $1.15 \%$ \\
\hline $\begin{array}{c}\text { Bottom Face of the } \\
\text { beam }\end{array}$ & -10 & -10 & $0 \%$ \\
\hline
\end{tabular}

Table 1Initial temperature load versus hand calculation at top and bottumn faces of the beam

\begin{tabular}{|c|c|c|c|}
\hline & \multicolumn{3}{|c|}{ STRESSES } \\
\hline & $\begin{array}{c}\text { FEM-Predefined } \\
\text { Stress(MPa) }\end{array}$ & $\begin{array}{c}\text { Manual } \\
\text { Calculation(MPa) }\end{array}$ & \%Error \\
\hline Top Stresses & 3.51 & 3.46 & $1.44 \%$ \\
\hline Bottom Stresses & -8.8 & -10 & $12 \%$ \\
\hline
\end{tabular}

Table 2: Predefined stress versus hand calculation at top and bottom faces of the beam 


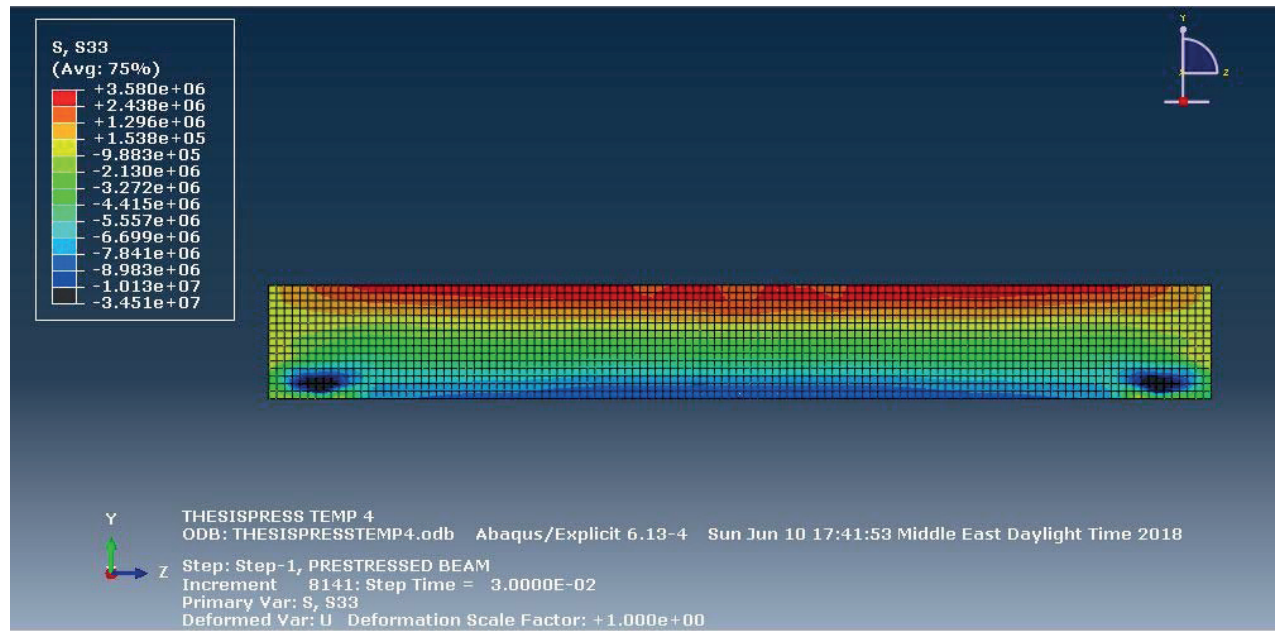

Figure 1:Beam Bottom Stresses For Initial Temperature load

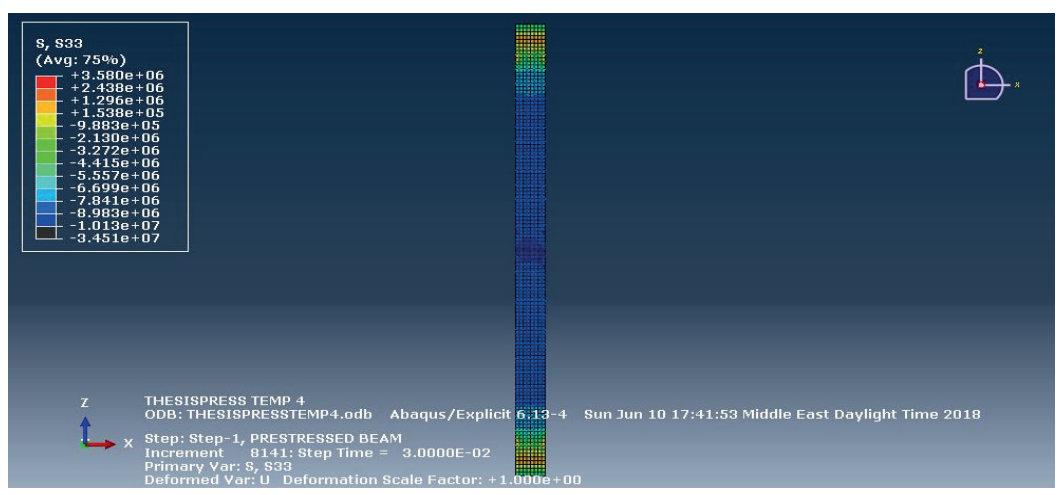

Figure 2: Beam Bottom Stresses For Initial Temperature load

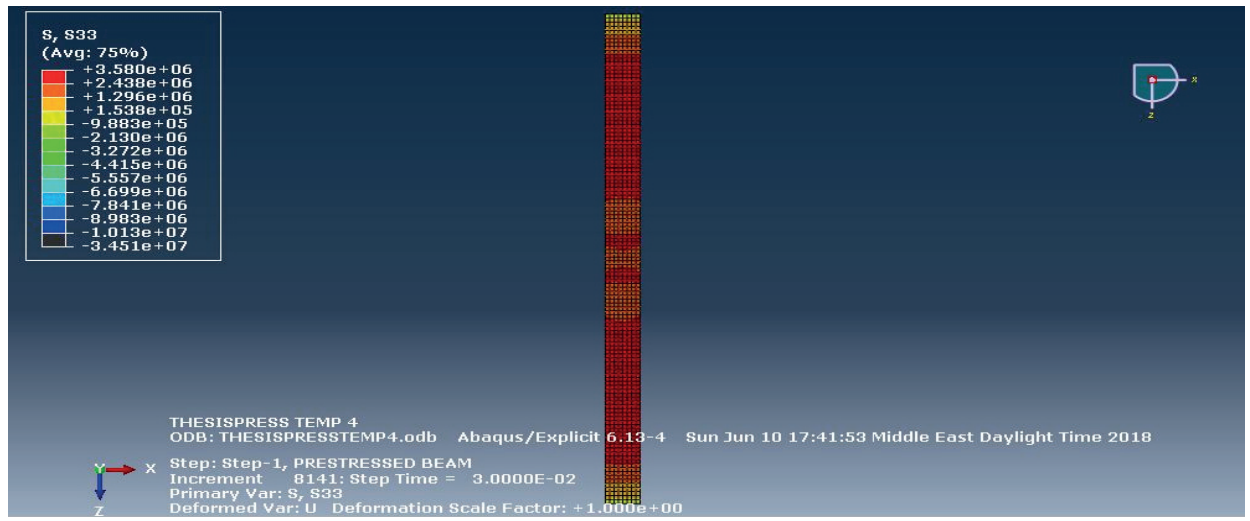

Figure 3: Beam Top Stresses 
Using Initial Temperature load, the finite element model showed an error of $1.15 \%$ in the top stresses with a decrease of $0.04 \mathrm{MPa}$, but no difference was observed at the bottom face giving zero error. Moreover, using predefined stresses, the finite element model showed higher values for top stresses with an increase of $0.05 \mathrm{MPa}$ giving an error of $1.44 \%$. On the other hand, stresses at bottom face showed $8.8 \mathrm{MPa}$, increasing the error to $12 \%$.

\subsection{Beam cambering}

The prestressing effect was successfully represented in both methods. To check these methods, a comparison was done between the equation of Nawy [12] camber calculation and the result from ABAQUS. The following equation was used to calculate the camber:

$$
\delta=\frac{P \cdot e}{E \cdot I} \times \frac{L^{2}}{8}+\frac{5 \cdot w \cdot L^{4}}{384 \cdot E \cdot I}
$$

Where "P" is the prestressing force, "e" is the eccentricity, "I" is the moment of inertia of the beam, and " $\mathrm{L}$ " is the span length of the beam.

\begin{tabular}{|c|c|c|c|}
\hline & \multicolumn{3}{|c|}{ CAMBERING } \\
\hline & $\begin{array}{c}\text { FEM- Initial Temperature load } \\
(\mathrm{mm})\end{array}$ & $\begin{array}{c}\text { Manual } \\
\text { Calculation(mm) }\end{array}$ & \%Error \\
\hline Cambering & 2.2 & 1.815 & $17.5 \%$ \\
\hline
\end{tabular}

Table 3: Initial Temperature load versus hand calculation cambering

\begin{tabular}{|c|c|c|c|}
\hline & \multicolumn{3}{|c|}{ CAMBERING } \\
\hline & FEM-Predefined Stress $(\mathrm{mm})$ & Manual Calculation(mm) & $\%$ Error \\
\hline Cambering & 2.23 & 1.815 & $18.86 \%$ \\
\hline
\end{tabular}

Table 4: Predefined stress versus hand calculation deflection

Using Initial Temperature load, the finite element model showed a cambering of $2.2 \mathrm{~mm}$ compared to $1.815 \mathrm{~mm}$ computed using hand calculation, which gives an error of $17.5 \%$

On the other hand, predefined stress showed a maximum cambering of $2.23 \mathrm{~mm}$ compared to $1.815 \mathrm{~mm}$ in the manual calculation, which gives an error of $18.86 \%$

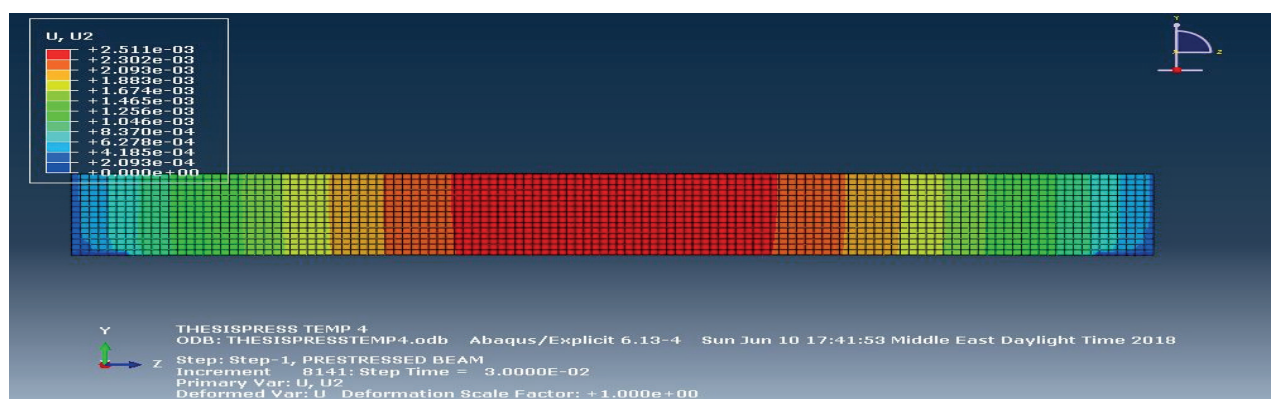

Figure 4: Cambering of prestressed beam using predefined initial stress 


\section{Analysis and Conclusion:}

The Initial Temperature load method showed higher accuracy in both bottom and top stresses than the predefined stress in comparison with manual calculation.

The Initial Temperature load method showed higher accuracy in cambering than the predefined stress in comparison with manual calculation.

As a conclusion, using Initial Temperature load to simulate initial pre-compression in prestressed beams shows more accurate results than using predefined stress.

\section{REFERENCES}

[1] Kang, T., Huang, Y., Computer Modeling of Post-Tensioned Structures, 4th International Conference on Computer Modelling and Simulation, 41, 45, 201.2

[2] Kwak,H., Kim, J., and Kim,S., Nonlinear analysis of prestressed concrete structures considering slip behavior of tendons, Computers and Concrete, Vol. 3, No. 1 43-64 (2006) .

[3] Chaudhari,S.V., Chakrabarti,M.A., Modeling of concrete for nonlinear analysis Using Finite Element Code ABAQUS, International Journal of Computer Applications (0975 - 8887) Volume 44- No.7, April 2012

[4] Arab,A., Sameh ,S., Badie ,b., Majid ,T. and Manzari ,b., A methodological approach for finite element modeling of pretensioned concrete members at the release of pretensioning, TY Lin International, Alexandria, VA, 22312, USA.

[5] Yehya Temsah, Ali Jahami, Jamal Khatib, M Sonebi, Numerical Analysis of a Reinforced Concrete Beam under Blast Loading, MATEC Web of Conferences 149(3):02063, January 2018.DOI: https://doi.org/10.1051/matecconf/201814902063.

[6] Yehya Temsah, Ali Jahami, Jamal Khatib, M Sonebi, Numerical Derivation of Iso-Damaged Curve for a Reinforced Concrete Beam Subjected to Blast Loading, MATEC Web of Conferences 149(3):02016, January 2018.DOI: https://doi.org/10.1051/matecconf/201814902016.

[7] Temsah, Y., Jahami, A., Khatib, J. and Firat, S. (2017). Numerical study for RC beams subjected to blast waves. In: 1st International Turkish World Engineering and Science Congress in Antalya. Antalya, Turkey.

[8] Temsah, Y., Jahami, A., Khatib, J. and Firat, S. (2017). Single Degree of Freedom Approach of a Reinforced Concrete Beam Subjected to Blast Loading. In: 1st International Turkish World Engineering and Science Congress in Antalya. Antalya, Turkey.

[9] AL RAWI, Y., TEMSAH, Y., GHANEM, H., JAHAMI, A. and ELANI, M. (2018). THEEFFECT OF IMPACT LOADS ON PRESTRESSED CONCRETE SLABS. In: The Second European and Mediterranean Structural Engineering and Construction Conference. [online] ISEC. Available at: https://www.isec-society.org/ISEC_PRESS/EURO_MED_SEC_02/html/STR-28.xml [Accessed 6 Aug. 2018].

[10] ELANI, M., TEMSAH, Y., GHANEM, H., JAHAMI, A. and AL RAWI, Y. (2018). THE EFFECT OF SHEAR REINFORCEMENT RATIO ON PRESTRESSED CONCRETE BEAMS SUBJECTED TO IMPACT LOAD. In: The Second European and Mediterranean Structural Engineering and Construction Conference. [online] ISEC. Available at: society.org/ISEC_PRESS/EURO_MED_SEC_02/html/STR-33.xml [Accessed 6 Aug. 2018].

[11] Jahami A H., Temsah Y A., Khatib J., Sonebi M., "Numerical Study For The Effect of Carbon Fiber Reinforced Polymers (CFRP) Sheets on Structural Behavior of Posttensioned Slab Subjected to Impact Loading", Proceedings of the Symposium on Concrete Modelling - CONMOD2018 , RILEM PRO 127, Edited by Erik Schlangen et al., 2018, pp. 259-267.

[12] Lublinear, J., Oliver, J., Oller, S., Onate, E., 1989. A plastic-damage model for concrete, Solids and Structures, Vol. 25, No. 3, pp. 299-326. 7.

[13] Lee, J., Fenves, G., 1998. Plastic-damage model for cyclic loading of concrete structure, Engineering 
Mechanics, Vol. 124, No. 8, pp. 892-900.

[14] Ren,W.,Sneed,L.,Yang,Y., and He,R., Numerical Simulation of Prestressed Precast Concrete Bridge Deck Panels Using Damage Plasticity Model, International Journal of Concrete Structures and Materials Vol.9, No.1, pp.45-54, March 2015

[15]Nawy,E., Prestressed Concrete: A Fundamental Approach, 5th Edition Prentice Hall, 2016. 